\title{
Repeated exposure to conditioned fear stress increases anxiety and delays sleep recovery following exposure to an acute traumatic stressor
}

\author{
Benjamin N. Greenwood ${ }^{1 \dagger}{ }^{\dagger}$, Robert S. Thompson ${ }^{2,3}{ }^{\dagger}$, Mark R. Opp $^{4}$ and Monika Fleshner ${ }^{2,3 *}$ \\ ${ }^{1}$ Department of Psychology, University of Colorado Denver, Denver, CO, USA \\ 2 Department of Integrative Physiology, University of Colorado Boulder, Boulder, CO, USA \\ ${ }^{3}$ Center for Neuroscience, University of Colorado Boulder, Boulder, CO, USA \\ ${ }^{4}$ Department of Anesthesiology and Pain Medicine, University of Washington, Seattle, WA, USA
}

\section{Edited by:}

Stefan Oskar Reber, University of

UIm, Germany

Reviewed by:

Robert Murison, University of Bergen, Norway

Ilia N. Karatsoreos, Washington State University, USA

\section{*Correspondence:}

Monika Fleshner, Department of Integrative Physiology, Center for Neuroscience, Boulder, CO, USA e-mail: fleshner@colorado.edu

${ }^{+}$Benjamin N. Greenwood and Robert S. Thompson have contributed equally to this work.

\begin{abstract}
Repeated stressor exposure can sensitize physiological responses to novel stressors and facilitate the development of stress-related psychiatric disorders including anxiety. Disruptions in diurnal rhythms of sleep-wake behavior accompany stress-related psychiatric disorders and could contribute to their development. Complex stressors that include feareliciting stimuli can be a component of repeated stress experienced by human beings, but whether exposure to repeated fear can prime the development of anxiety and sleep disturbances is unknown. In the current study, adult male F344 rats were exposed to either control conditions or repeated contextual fear conditioning for 22 days followed by exposure to no, mild (10), or severe (100) acute uncontrollable tail shock stress. Exposure to acute stress produced anxiety-like behavior as measured by a reduction in juvenile social exploration and exaggerated shock-elicited freezing in a novel context. Prior exposure to repeated fear enhanced anxiety-like behavior as measured by shock-elicited freezing, but did not alter social exploratory behavior. The potentiation of anxiety produced by prior repeated fear was temporary; exaggerated fear was present 1 day but not 4 days following acute stress. Interestingly, exposure to acute stress reduced rapid eye movement (REM) and non-REM (NREM) sleep during the hours immediately following acute stress. This initial reduction in sleep was followed by robust REM rebound and diurnal rhythm flattening of sleep/wake behavior. Prior repeated fear extended the acute stress-induced REM and NREM sleep loss, impaired REM rebound, and prolonged the flattening of the diurnal rhythm of NREM sleep following acute stressor exposure. These data suggest that impaired recovery of sleep/wake behavior following acute stress could contribute to the mechanisms by which a history of prior repeated stress increases vulnerability to subsequent novel stressors and stress-related disorders.
\end{abstract}

Keywords: REM, NREM, anxiety, diurnal rhythm, conditioning, classical, sleep, chronic stress

\section{INTRODUCTION}

Although acute activation of the stress response evolved to enhance chances of survival, excessive, chronic, or repeated activation of the stress response can negatively impact central and peripheral physiological systems (1-3) and is a significant risk factor for the development of stress-related mental illness including depression, anxiety, and post-traumatic stress disorder [PTSD; (4-6)]. One way that repeated stressor exposure could facilitate psychiatric disorders is by sensitizing responses to novel stressors. Indeed, individuals with PTSD display exaggerated startle (7-9), autonomic $(10,11)$, and in some cases hypothalamic-pituitary-adrenal axis $(12,13)$ responses to aversive stimuli. Similarly, rodents exposed to repeated stressors can display exaggerated hormonal (14-16), autonomic $(17,18)$ and neuronal $(19,20)$, responses to acute, novel stressors. These exaggerated responses to novel stressors in rodents can occur concordantly with the development of anxietyand depression-like behaviors $(21,22)$.
Disruptions in diurnal rhythms of sleep-wake behavior and specific alterations in sleep architecture accompany stress-related psychiatric disorders and could contribute to their development (23-27). In fact, the Diagnostic and Statistical Manual for Mental Disorders lists sleep disturbance as diagnostic criteria for several types of anxiety disorders, and epidemiological studies reveal that insomnia is a risk factor for depression (28). Sleep architecture can be characterized by measuring stages of sleep using electroencephalogram (EEG). A typical night of sleep consists of episodes of non-rapid eye movement (NREM) sleep, which includes slow-wave sleep and rapid eye movement (REM) sleep. Individuals suffering from panic disorder have disruptions in sleep that include reduced percent (\%) time spent in NREM sleep $(29,30)$. Depressed patients generally display increased \% REM, sleep fragmentation, and reduced \% NREM $(31,32)$. Disturbed slow wave (33) and REM (34-37) sleep is also considered a hallmark symptom (38) and post-trauma predictor (39) of PTSD. 
In rodents, stressor exposure can disrupt REM and NREM sleep and flatten diurnal rhythms of sleep/wake behavior [see Ref. (40, 41) for reviews]. Finally, manipulations of the sleep/wake cycle can alleviate depression symptoms $(42,43)$. Together, these data suggest that factors that increase vulnerability to sleep disruption could contribute to the development of stress-related psychiatric disorders.

Stressors that are unpredictable and uncontrollable are the most potent in terms of their deleterious consequences on emotion (44) and sleep (41). Rats exposed to a series of uncontrollable tail shocks, but not an equal number and intensity of controllable tail shocks, for example, display behaviors resembling anxiety and depression including a reduction in social exploratory behavior (45), an increase in fear conditioning (46), and a deficit in goaldirected learning in a shuttle-box escape task (44). Exposure to this same uncontrollable stressor can also flatten diurnal rhythms of activity and physiology (47), and increase sleep fragmentation and suppress REM (Thompson et al., unpublished). Similarly, repeated uncontrollable foot shock stress reduces overall time spent in REM in mice during the $20 \mathrm{~h}$ period following each uncontrollable shock session or re-exposure to the shock context (48). Interestingly, stress-buffering manipulations such as voluntary exercise prevent both the anxiety- and depression-like behavioral (49-51) and sleep-disrupting consequences of uncontrollable stress in rats. Although it is clear that stress can impact sleep depending on the nature of the stressor (41), whether a history of repeated stressor exposure can sensitize sleep disruption in response to a novel, acute uncontrollable stressor remains unknown.

In the current study, adult male F344 rats were exposed to control conditions or repeated contextual fear conditioning for 22 days followed by exposure to no, mild (10), or severe (100) acute uncontrollable tail shock stress. Complex stressors that include exposure to fear-eliciting stimuli can be a component of repeated stress experienced by human beings. We have previously reported that repeated exposure to fear conditioning can sensitize physiological responses to acute uncontrollable stress and exacerbate uncontrollable stress-induced disruptions in diurnal rhythms of heart rate (HR) and core body temperature (CBT) (18). The goal of the current study was to determine whether repeated exposure to conditioned fear can also prime the development of anxiety and sleep disturbances following exposure to an acute uncontrollable stressor.

\section{MATERIALS AND METHODS \\ ANIMALS}

A total of 141 adult, male F344 rats (Harlan Laboratories) weighing 200-230 g upon arrival were housed under controlled temperature $\left(22^{\circ} \mathrm{C}\right)$ and humidity. The animals were maintained on a $12: 12 \mathrm{~h}$ light/dark cycle (lights on 7:00 a.m. to 7:00 p.m). All rats were single housed in Nalgene Plexiglas cages $(45 \mathrm{~cm} \times 25.2 \mathrm{~cm} \times 14.7 \mathrm{~cm})$ and were allowed to acclimate to the housing conditions for 1 week before start of experimental procedures. Rats had ad libitum access to food and water and were weighed three times per week. All experimental procedures were performed during the inactive (light) phase of the light:dark cycle and animals were handled during the 1 week acclimation period. Animal discomfort was minimized during all procedures. Experimental protocols for these studies were approved by the University of Colorado Animal Care and Use Committee.

\section{REPEATED FEAR}

Exposure to repeated contextual fear was performed as previously described in detail $(18,52)$ Briefly, rats were placed into a conditioning chamber $(46 \mathrm{~cm} \times 20.7 \mathrm{~cm} \times 20 \mathrm{~cm})$ on day 0 for $5 \mathrm{~min}$ in order to acquire a memory of the context, after which rats received three, $2 \mathrm{~s}, 1.5 \mathrm{~mA}$ foot shocks ( $1 \mathrm{~min}$ ITI). This initial contextual fear conditioning occurred at $1000 \mathrm{~h}$. Rats were returned to their home cages immediately following initial conditioning and after every subsequent re-exposure to the conditioned context. Starting $24 \mathrm{~h}$ following initial conditioning (day 1), rats were repeatedly exposed to the conditioned context twice a day for 22 days: once in the a.m. and once in the p.m. Each exposure was $20 \mathrm{~min}$ in duration and occurred between 8:00 and 12:00 h (a.m. session) and 12:00 and 5:00 h (p.m. session). The time of each a.m. and p.m. exposure was chosen randomly in order to reduce predictability. Freezing, defined by the absence of movement except that required for respiration, was scored during each re-exposure session using a random sampling procedure, whereby rats were either scored as freezing or not freezing every $10 \mathrm{~s}$. To prevent extinction of fear, minimal numbers of re-instatement foot shocks were used to reinstate contextual conditioned fear. When average freezing during an a.m. session fell below 50\%, all rats were administered a single re-instatement foot shock $(2 \mathrm{~s}, 1.5 \mathrm{~mA})$ at the end of the p.m. re-exposure session.

\section{INESCAPABLE TAIL SHOCK STRESS}

After 22 days of no repeated fear or repeated fear exposure, rats either remained in their home cages and were not exposed to acute stress ( 0 tail shocks), or were exposed to 10 or 100 inescapable tail shocks as previously described (18). On the day of exposure to tail shock, rats assigned to the tail shock groups were transported to a separate room, placed in Broome-style Plexiglas restraining tubes $(23.4 \mathrm{~cm}$ long and $7.0 \mathrm{~cm}$ in diameter), and exposed to 10 or $100,5 \mathrm{~s}, 1.5 \mathrm{~mA}$ inescapable tail shocks. Shocks were delivered at a variable-60 s ITI between 8:00 a.m. and 11:00 a.m. Rats were immediately returned to their home cages following termination of the appropriate number of shocks (10 or 100). Inescapable tail shock was used as the acute novel stressor in these experiments because it produces reliable behaviors in rodents resembling human symptoms of stress-related psychiatric disorders $(44,45)$, and we have previously reported that prior repeated fear stress sensitizes physiological responses to tail shock stress (18).

\section{BEHAVIORAL TESTING}

Measures of juvenile social exploration and shock-elicited freezing were obtained sequentially as previously described (53). Testing for baseline juvenile social exploration occurred 1 week prior to uncontrollable stress. During social exploration testing, each adult experimental subject was placed into separate plastic cages identical to their home cages with bedding and a plastic, filter-top lid between 7:00 a.m. and 8:00 a.m. After $1 \mathrm{~h}$, a 28-32-day-old male juvenile was introduced to the cage for $3 \mathrm{~min}$ and exploratory behaviors (sniffing, pinning, and allogrooming) were timed by an observer blind to treatment. After the test, the juvenile was 
removed and the experimental rat was returned to the home cage. Baseline testing was used to reduce neophobia to the social exploration procedure.

One week after baseline testing, and either 1 or 4 days following 0,10 , or 100 tail shocks, rats were again tested for social exploratory behaviors as described for the baseline test. Different juvenile rats were used for the two social exploration tests, so that experimental rats were not exposed repeatedly to the same juvenile. Social exploration occurred prior to shock-elicited freezing so that shock administered during the fear test would not interfere with social exploration behavior.

Following the completion of social exploration testing, rats were transferred to novel, brightly lit chambers that differed in size, lighting, odor, and background noise from the conditioning chambers used for repeated fear stress. Freezing behavior was observed for $10 \mathrm{~min}$ immediately after placement of the rats into the chambers. Rats then received two, $1 \mathrm{~s}$, foot shocks $(0.7 \mathrm{~mA}$, $1 \mathrm{~min}$ ITI) followed by a $20 \mathrm{~min}$, post-shock freezing observation period. Freezing immediately following shock presentation is a measure of fear conditioned to cues present in the shuttle box (54). Reduction in juvenile social exploration $(45,55)$ and enhanced shock-elicited freezing $(56,57)$ represent rodent analogs of socialand fear-related anxiety behaviors, respectively.

\section{BIOTELEMETRY SURGERIES}

F40-EET biotelemetry transmitters (Data Sciences International, St. Paul, MN, USA) were implanted into animals used in Experiment 3 as previously described $(18,47,52)$. Following ketamine (i.p. $75.0 \mathrm{mg} / \mathrm{kg}$ ), and medetomidine (i.p. $0.5 \mathrm{mg} / \mathrm{kg}$ ) anesthesia, a midline incision was made approximately $5.0 \mathrm{~cm}$ in length on the ventral abdominal wall. Biopotential leads were passed through the ventral abdominal wall and then the transmitter was sutured to the ventral abdominal wall. The EEG leads were placed as previously described in telemetry studies of mice $(58,59)$. Briefly, insulated leads were passed subcutaneously to the base of the skull, where they were attached to pan head stainless steel screws (Plastics One Inc.), which served as EEG recording electrodes. Screws were placed according to the Rat Brain Atlas in Stereotaxic Coordinates by Paxinos and Watson (60) at anterior $2.0 \mathrm{~mm}$; lateral $2.5 \mathrm{~mm}$ and posterior $5.5 \mathrm{~mm}$; lateral $3.0 \mathrm{~mm}$ from Bregma using standard stereotaxic methods (61). Screws and leads were embedded in dental acrylic to ensure the integrity of the recording signal. Immediately following surgery, rats were given meloxicam $(1.0 \mathrm{mg} / \mathrm{kg} \mathrm{s.c.})$ for analgesia after which they recovered on a heating pad at $37^{\circ} \mathrm{C}$ until ambulatory. Once ambulatory, rats were returned to their home cages and given one $2.0 \mathrm{mg}$ rimadyl tablet (Bio-Serv) and several fruity bites (Bio-Serv). Animals were allowed to recover for 1 week before the start of repeated exposure to conditioned fear.

\section{BIOTELEMETRY DATA ACOUISITION AND ANALYSIS}

The F40-EET transmitter (DSI) allows in vivo real-time measurement of locomotor activity (LA), HR, CBT, and EEG in freely moving animals. Biotelemetry recordings were acquired/analyzed using Dataquest ART 4.3 Gold Acquisition/Analysis Software (Data Sciences International, St. Paul, MN, USA), as previously described $(18,52)$. Analyses of the sleep/wake cycles were performed using the automated Neuroscore 2.1.0 software (Data Sciences International, St. Paul, MN, USA). The trace EEG signal was subjected to fast Fourier Transformation (FFT), yielding spectra between 0.5 and $30 \mathrm{~Hz}$ in $0.5-\mathrm{Hz}$ frequency bins. The delta frequency band was defined at $0.5-4.5 \mathrm{~Hz}$ and the theta frequency band was defined as $6.0-9.0 \mathrm{~Hz}$, as previously described (59). Arousal state was scored in 10-s epochs and classified as NREM, REM, or wake on the basis of state-dependent changes in multiple parameters, including the EEG, LA, HR, and body temperature, as previously described $(59,62)$. Wakefulness was defined on the basis of a low amplitude, mixed frequency EEG (delta $\approx$ theta) accompanied by body movements (i.e., activity), and increases in body temperature. NREM sleep was identified by increased absolute EEG amplitude with integrated values for the delta frequency band greater than those for the theta frequency and lack of body movements. Body temperature declines upon entry into NREM sleep until it reaches a regulated asymptote. REM was characterized by a low amplitude EEG with integrated values for the delta frequency band less than those for the theta frequency band. Any epochs containing artifact or electrical noise were tagged and excluded from subsequent spectral analysis. All sleep scoring was performed by an individual blind to treatment condition of the animal.

\section{EXPERIMENTAL DESIGN \\ Experiment 1}

Experiment 1 was designed to test the hypothesis that prior repeated fear stress sensitizes anxiety responses to novel acute stressor exposure. Rats were randomly assigned to the following groups: no repeated fear (home cage)/0 tail shocks $(n=7)$; home cage/10 tail shocks $(n=8)$; home cage/100 tail shocks $(n=8)$; repeated fear/0 tail shocks $(n=8)$; repeated fear/10 tail shocks $(n=8)$; repeated fear/100 tail shocks $(n=7)$. All rats were tested for anxiety-like behavior using social exploration and shockelicited freezing $24 \mathrm{~h}$ following tail shock exposure. Figure 1A shows the sequence of events followed during Experiment 1.

\section{Experiment 2}

Experiment 2 explored whether acute stress-induced anxiety-like behavior persisted longer following acute stress in rats previously exposed to repeated fear compared to home cage rats. Rats previously exposed to home cage or repeated fear conditions were exposed to 0 or 100 tail shocks and were then tested for anxietylike behaviors either 1 or 4 days later. Groups containing home cage and repeated fear rats not exposed to tail shock (the 0 tail shock groups) were split so that half of the rats were tested with the 1day group and the other half were tested with the 4-day group. No time-dependent effects were noted between the 0 tail shock rats tested at the 1 and 4 -day time points, so the time points were combined. Therefore, the home cage/ 0 tail shock and repeated fear $/ 0$ tail shock groups include rats tested at both the day 1 and day 4 time points. The following groups were tested: Home cage/0 $(n=8)$; home cage/ 1 day after 100 tail shocks $(n=8)$; home cage/4 days after 100 tail shocks $(n=8)$; repeated fear/0 $(n=8)$; repeated fear/ 1 day after 100 tail shocks $(n=7)$; repeated fear/4 days after 100 tail shocks $(n=8)$. A time line for the procedures used in Experiment 2 can be found in Figure 1B. 
A Experiment 1

Social exploration and

shock-elicited freezing

Home cage or repeated fear

treatment (re-exposure to fear context $2 x /$ day)

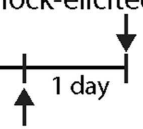

Contextual

fear conditioning

Exposure to 0,10 , or 100

uncontrollable shocks

B Experiment 2

Social exploration and

Bexperiment 2

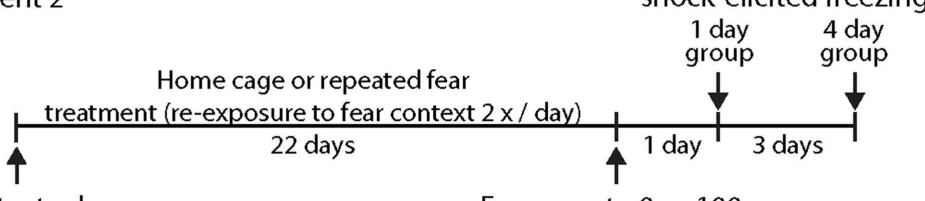

Contextual

fear conditioning

Exposure to 0 or 100

uncontrollable shocks

C

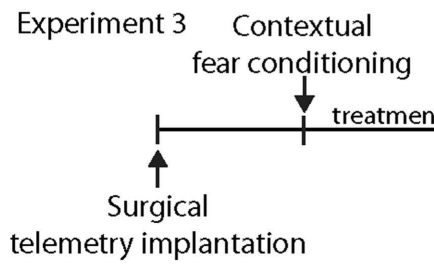

Biotelemetric recording

of physiology and sleep

Home cage or repeated fear

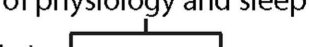
22 days

telemetry implantation

Exposure to 0, 10 or 100

uncontrollable shocks

FIGURE 1 | Time lines depicting the series of events used in Experiment 1 (A), Experiment 2 (B), and Experiment 3 (C).

\section{Experiment 3}

Rats implanted with F40-EET transmitters were exposed to home cage or repeated fear conditions for 22 days, followed by 0,10 , or 100 tails shocks. Data were recorded starting 1 week after telemetry implantation and continued throughout the remainder of the experiment. Body weight, freezing behavior during repeated fear stress, HR, body temperature, and activity obtained from the rats used in this experiment have been published previously (18). Here, EEG and physiological data were analyzed starting at clock time 1:00 p.m. ( $2 \mathrm{~h}$ following the termination of tail shocks) and continued for 3 days thereafter. We waited approximately $2 \mathrm{~h}$ following the termination of tail shock stress in order to avoid the disruption in the telemetry signal produced by moving the rats from the stress induction room back to their home cages. Moreover, starting the analyses at the same clock time for all animals eased analyses of the data. Twelve of the initial 48 rats used in the study were dropped from analyses due to loss or interference with the EEG signal, yielding the following groups: home cage/0 tail shocks $(n=5)$; home cage/10 tail shocks $(n=7)$; home cage/100 tail shocks $(n=6)$; repeated fear/0 tail shocks $(n=5)$; repeated fear/10 tail shocks $(n=7)$; repeated fear/100 tail shocks $(n=6)$. A time line for the procedures used in Experiment 3 can be found in Figure 1C.

\section{STATISTICAL ANALYSIS}

Body weight data were analyzed using repeated measures ANOVA. Average time spent exploring during the $3 \mathrm{~min}$ social exploration test and average $\%$ freezing during the 20 min post-shock freezing period in Experiment 1 were analyzed using 2 (home cage, repeated fear $) \times 3(0,10,100$ tail shocks $)$ ANOVAs or, for Experiment 2, 2 (home cage, repeated fear) $\times 3$ (no acute stress, 1 day after 100 tail shocks, 4 days after 100 tail shocks) ANOVAs. Percent time spent in REM, NREM, and wake during the remaining $6 \mathrm{~h}$ of the light cycle starting approximately $2 \mathrm{~h}$ following termination of acute stress were collapsed into $1 \mathrm{~h}$ blocks and analyzed with 2 (home cage, repeated fear $) \times 3(0,10,100$ tail shocks $)$ repeated measures ANOVA. Subsequent percent time spent in REM, NREM, and wake were collapsed into $12 \mathrm{~h}$ blocks and compared with $2 \times 3$ ANOVAs. Light and dark cycles were analyzed independently. Diurnal differences of average \% REM, \% NREM, and \% wake, calculated by subtracting the average dark cycle value from the average light cycle value, were compared using $2 \times 3$ ANOVAs. Fisher's PLSD post hoc analyses were used as appropriate. Group means were considered different when $p<0.05$.

\section{RESULTS}

\section{FREEZING DATA AND BODY WEIGHT}

Rats exposed to repeated conditioned fear stress for 22 days displayed freezing behavior upon each re-exposure to the conditioned context (Figure 2A). Rats in both Experiments 1 and 2 required 6 foot shocks to maintain levels of freezing above $50 \%$. Body weights of rats used in Experiments 1 and 2 are shown in Figures 2B,C, respectively. Both groups gained weight over time [Experiment 1, $F(8,352)=467.1 ; p<0.0001$; Experiment $2, F(8,360)=704.5$; $p<0.0001]$, but rats exposed to repeated fear stress gained less weight over time compared to rats exposed to home cage treatment [Experiment 1, $F(8,352)=57.56 ; p<0.0001$; Experiment $2, F(8,360)=37.97 ; p<0.0001]$. Freezing and body weight data from rats used in Experiment 3 have been published previously (18) and thus are not shown. 


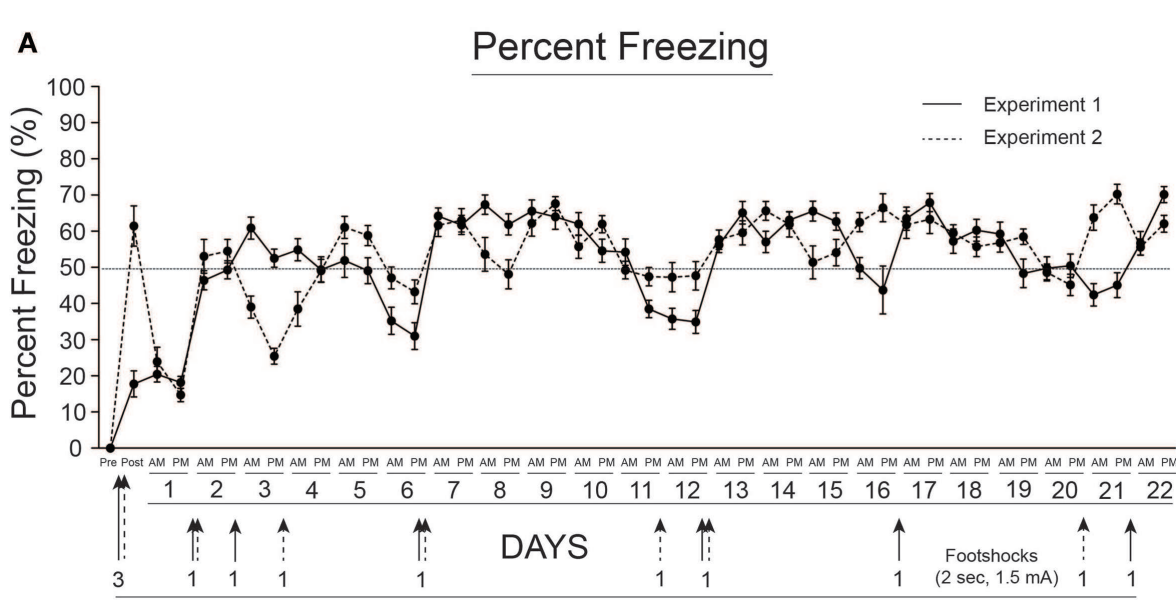

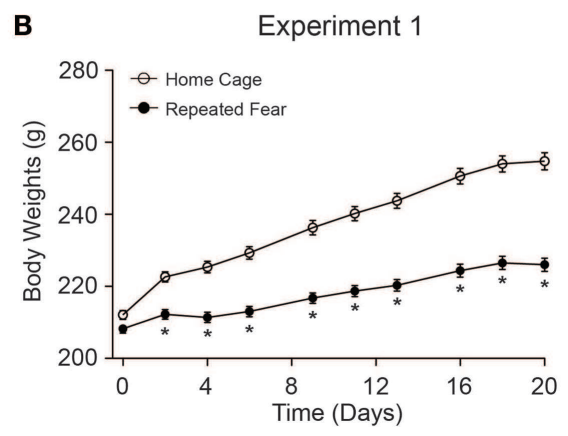

FIGURE 2 | Freezing behavior and body weights for rats used in

Experiments 1 and 2. (A) Freezing was scored before (pre) and after (post) administration of 3 foot shocks during contextual fear conditioning on day 0 . Rats were re-exposed to the conditioned context twice a day, early (a.m.), or late (p.m.) during the light cycle, for 22 days. Re-instatement shocks (denoted

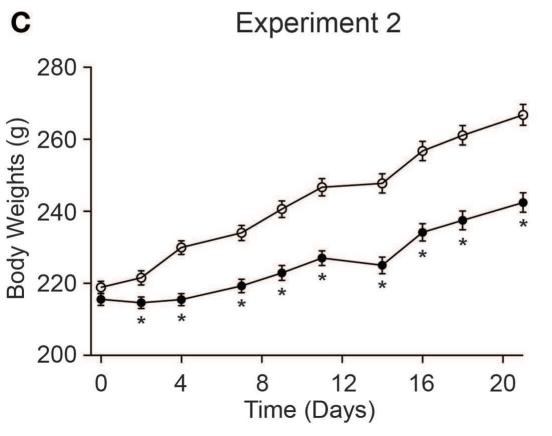

by arrows) were administered at the end of the p.m. session when average freezing fell below $50 \%$. The number of shocks administered is noted next to each arrow. Rats in both Experiment 1 (B) and Experiment 2 (C) exposed to repeated fear stress gained less weight over time relative to home cage control rats. ${ }^{*} p<0.05$ relative to home cage control.

\section{PRIOR EXPOSURE TO REPEATED FEAR STRESS INCREASES ANXIETY AS MEASURED BY SHOCK-ELICITED FREEZING}

Twenty four hours following exposure to 0,10 , or 100 tail shocks, rats used in Experiment 1 were tested for social exploratory behavior and shock-elicited fear. Consistent with prior reports (50, $53,55)$, exposure to acute stress reduced social exploration $[F(2$, $40)=8.48 ; p=0.0008$; Figure 3A] and increased shock-elicited freezing $[F(2,40)=3.54 ; p=0.03$; Figure 3B $]$. Only 100 tail shocks reduced social exploration $(p=0.02)$ and increased fear $(p=0.01)$. The reduction in social exploration $(p=0.07)$ and the increase in fear $(p=0.07)$ following 10 shocks failed to reach significance. A history of repeated fear had no impact on social exploratory behavior $[F(1,40)=1.13 ; p>0.05]$, thus acute stress reduced social exploratory behavior equally regardless of history of repeated fear. In contrast, rats exposed to repeated fear displayed more fear than rats exposed to home cage treatment $[F(1$, $40)=3.82 ; p<0.05]$. These effects occurred in the absence of gross changes in LA. Neither acute tail shock stress $[F(2,40)=1.97$; $p>0.05]$ nor repeated fear $[F(1,40)=1.62 ; p>0.05]$ altered the number of spontaneous cage crosses during social exploration testing (data not shown).
In Experiment 2, rats exposed to repeated fear or home cage treatments were tested for anxiety-like behavior either 1 or 4 days following 0 or 100 tail shocks. Results similar to those observed in Experiment 1 were seen here. Exposure to acute stress reduced social exploration $[F(2,41)=9.38 ; p=0.0004$; Figure 4A $]$ and increased shock-elicited freezing $[F(2,41)=4.75$; $p=0.01$; Figure $4 \mathrm{~B}]$. Regardless of history of prior repeated fear exposure, a reduction in social exploratory behavior was observed both $1(p=0.003)$ and $4(p=0.0002)$ days following tail shock stress, whereas the increase in shock-elicited freezing was only present when rats were tested 1 day following tail shock $(p=0.01)$. Although a history of repeated fear had no impact on social exploration $[F(1,41)=0.007 ; p>0.05]$, exaggerated shockelicited freezing was again observed in rats exposed to repeated fear stress $[F(1,41)=9.52 ; p=0.004]$. This exaggerated fear produced by repeated fear stress relative to home cage treatment was temporary. Exaggerated fear produced by repeated fear stress was present in rats not exposed to acute tail shock stress $(p=0.01)$ and 1 day $(p=0.02)$, but not 4 days $(p>0.05)$, following acute tail shock stress. Again, neither acute tail shock stress $[F(2,41)=3.07$; $p>0.05]$ nor repeated fear $[F(1,41)=0.16 ; p>0.05]$ altered the 

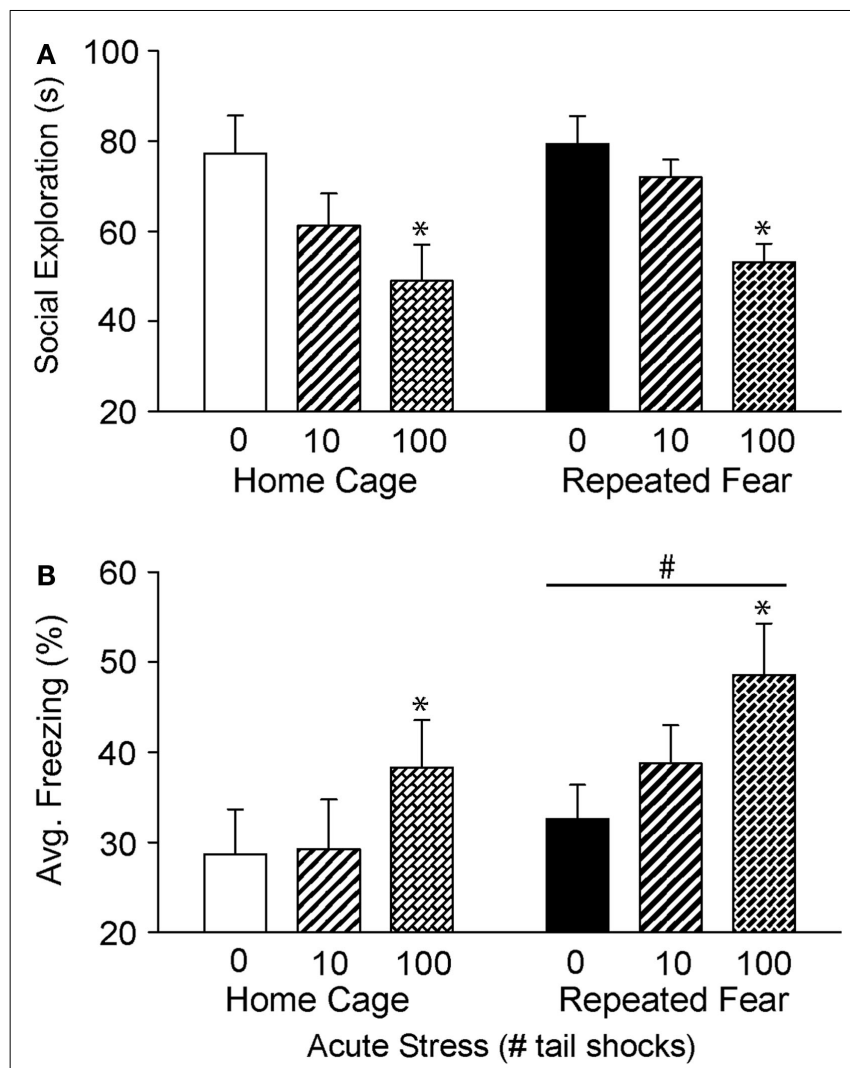

FIGURE 3 | Effects of prior repeated fear stress on anxiety behavior following mild or severe acute stress. Following 22 days of no repeated fear (home cage) or repeated fear stress (repeated fear), rats were exposed to no acute stress (0), mild (10 uncontrollable tail shocks; 10), or severe (100 uncontrollable tail shocks; 100) acute stress. Juvenile social exploration (A) and shock-elicited freezing (B) were measured $24 \mathrm{~h}$ later in a novel environment. ${ }^{*} p<0.05$ relative to 0 groups; \#main effect of repeated fear stress $(p<0.05)$.

number of cage crosses during social exploration testing (data not shown).

\section{REPEATED FEAR PROLONGS REM AND NREM SLEEP LOSS IMMEDIATELY FOLLOWING ACUTE STRESS}

The \% time spent in REM, NREM, and wake during the remaining $6 \mathrm{~h}$ of the light cycle starting approximately $2 \mathrm{~h}$ following the termination of acute tail shock stress are shown in Figure $\mathbf{5}$. Acute stress reduced \% REM (Figures 5A,B) and \% NREM (Figures 5C,D) in both home cage and repeated fear groups during the first few hours following acute stress. The reduction in \% REM and \% NREM following acute stress persisted longer in rats that had been previously exposed to repeated fear stress compared to home cage treatment. This was especially true for \% REM. In contrast to the effect of acute stress in home cage rats, which only persisted for $2 \mathrm{~h}$, both 10 and 100 tail shocks suppressed \% REM in repeatedly stressed rats for $5 \mathrm{~h}$. These results were confirmed with repeated measures ANOVA, which revealed a significant main effect of acute stress $[F(2,30)=4.22 ; p=0.02]$ and significant interactions between
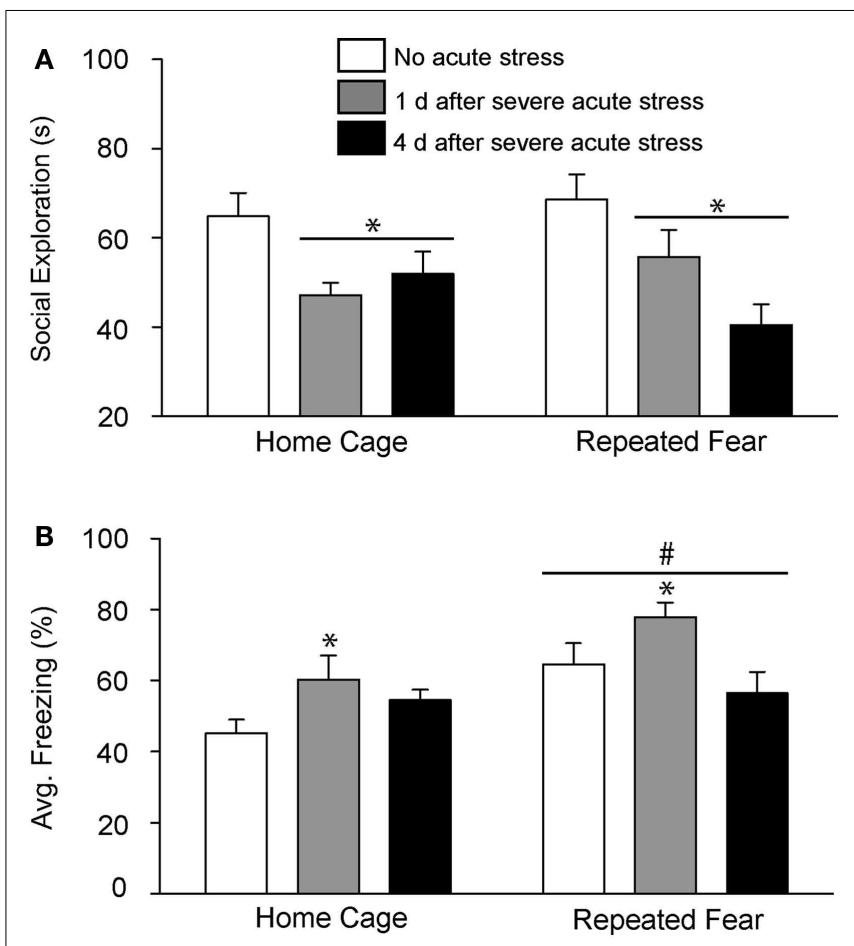

FIGURE 4 | Effects of prior repeated fear stress on persistence of anxiety behavior following severe acute stress. Following 22 days of no repeated fear (home cage) or repeated fear stress (repeated fear), rats were either exposed to no acute stress or to 100 uncontrollable tail shocks (acute severe stress). Juvenile social exploration (A) and shock-elicited freezing (B) were measured either 1 or 4 days later in a novel environment. ${ }^{*} p<0.05$ relative to 0 groups; \#main effect of repeated fear stress $(p<0.05)$.

acute stress and time $(10,150)=2.5 ; p=0.008)$ and acute stress, time, and repeated fear $[F(10,150)=2.41 ; p=0.01]$ on $\%$ REM; and significant main effects of repeated fear $[F(1,30)=5.45$; $p=0.02]$, acute stress $[F(2,30)=5.6 ; p=0.02]$, and significant interactions between repeated fear and time $[F(5,150)=2.68$; $p=0.02]$ and acute stress and time $[F(10,150)=4.29 ; p<0.0001]$ on \% NREM. The acute stress-induced reduction in REM and NREM sleep was accompanied by a detectible increase in wakefulness (Figures 5E,F). ANOVA revealed significant main effects of repeated fear stress $[F(1,30)=7.32 ; p=0.01]$ and acute stress $[F(2,30)=6.9 ; p=0.005]$; and a significant interaction between acute stress and time $[F(10,150)=3.08 ; p<0.0001]$. The home cage and repeated fear groups not exposed to acute stress (the 0 groups) did not differ in any parameter measured. See graphs for results of post hoc comparisons.

\section{PRIOR EXPOSURE TO REPEATED FEAR IMPAIRS REM REBOUND FOLLOWING ACUTE STRESS}

The \% REM, \% NREM, and \% wake during the $48 \mathrm{~h}$ following the beginning of the first night cycle after acute stress are shown in $12 \mathrm{~h}$ blocks in Figure 6. Consistent with REM rebound following periods of REM sleep loss $(63)$ and stress $(64,65)$, acute stress increased \% REM during the first $[F(2,30)=14.8$; $p<0.0001 ;$ Figure 6A] and second $[F(2,30)=3.97 ; p=0.03$; 

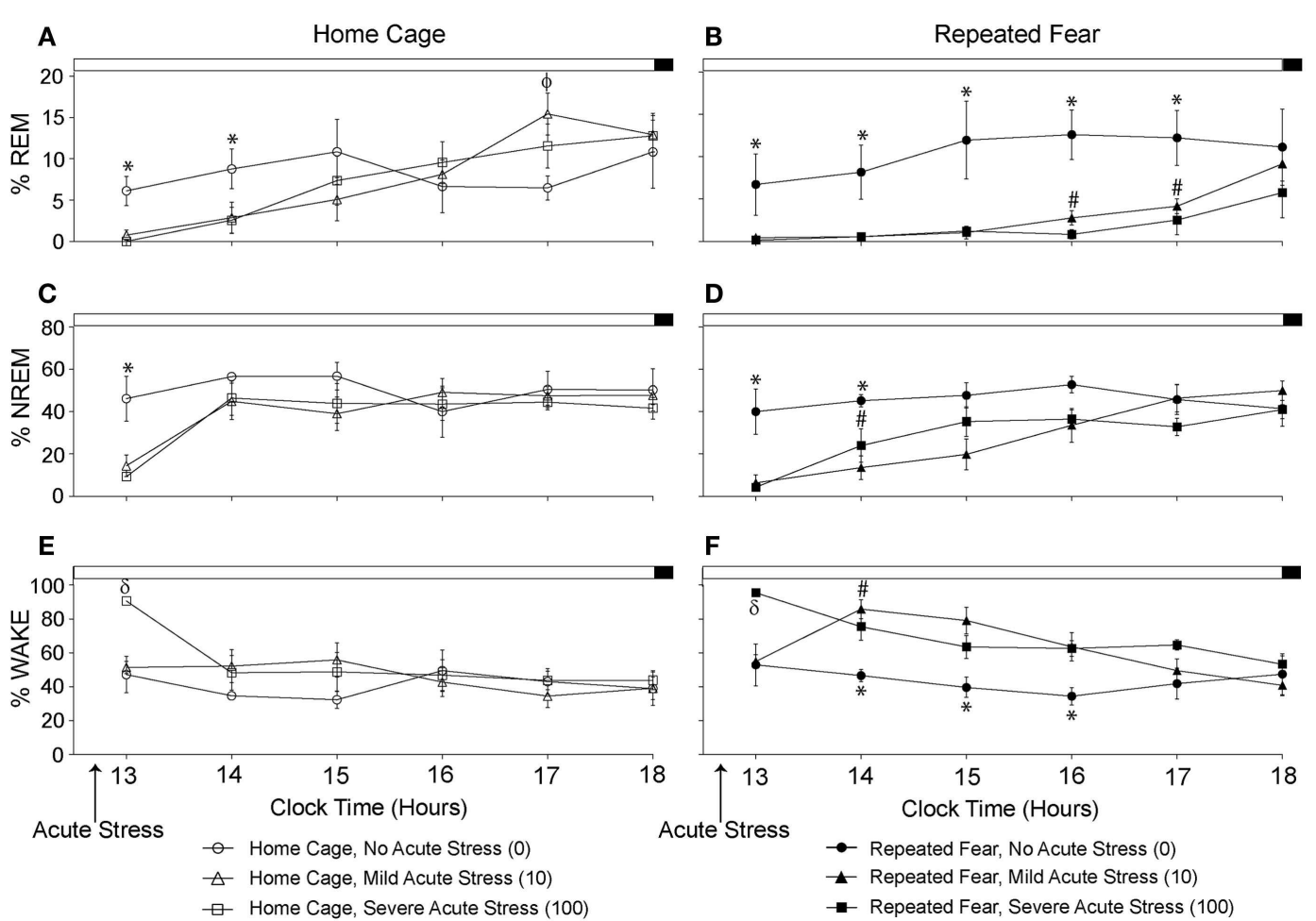

FIGURE 5 | Effects of repeated fear stress on sleep/wake behavior during the remainder of the light cycle following acute stressor exposure.

Following 22 days of no repeated fear (home cage) or repeated fear stress (repeated fear), rats were exposed to no acute stress (0), mild (10

uncontrollable tail shocks; 10), or severe (100 uncontrollable tails shocks; 100) acute stress. Percent time spent in rapid eye movement $[R E M ;(\mathbf{A}, \mathbf{B})]$ sleep, non-rapid eye movement [NREM; (C,D)] sleep, and wake (E,F) were determined in the home cage during the remainder of the light cycle starting approximately $2 \mathrm{~h}$ following the termination of acute tail shock stress. ${ }^{*} p<0.05$ relative to respective 10 and 100 groups; $\# p<0.05$ relative to home cage/10 and home cage/100 groups; $\phi p<0.05$ relative to home cage/0 group; $\delta p<0.05$ relative to respective 0 and 10 groups.
Figure 6C] $12 \mathrm{~h}$ dark cycles following acute stress. The \% REM in the light cycle was not impacted by acute or repeated fear stress (Figures 6B,D); however, the effect of acute stress on \% REM in the second light cycle following acute stress just missed significance $(p=0.06)$. Repeated fear impaired the REM rebound that occurred in acute stress groups during the first dark cycle that followed acute stress (Figure 6A). This was confirmed with ANOVA, which revealed a significant main effect of repeated fear $[F(1$, $30)=8.18 ; p=0.007]$ and a significant interaction between acute stress and repeated fear $[F(2,30)=4.75 ; p=0.01$; see Figure 6A for results of post hoc tests]. At no time did the home cage and repeated fear groups not exposed to acute stress differ in their $\%$ REM. Neither repeated fear nor acute stress altered \% NREM (Figures 6E-H).

The increase in \% REM following acute stress was paralleled by a reduction in wakefulness (Figures 6I-L). Both acute stress $[F(2$, $30)=5.59 ; p=0.008]$ and repeated fear $[F(1,31)=5.6 ; p=0.02]$ increased \% wake during the first dark cycle following acute stressor exposure (Figure 6I). At no other time following acute stress was \% wake altered by acute or repeated fear stress. The \% REM, $\%$ NREM, and \% wake in all groups resembled control values after the second light cycle that followed acute stress, thus these data are not shown.
PRIOR EXPOSURE TO REPEATED FEAR PROLONGS THE FLATTENING OF THE DIURNAL RHYTHM OF NREM SLEEP FOLLOWING ACUTE STRESS

To determine the impact of repeated fear and acute uncontrollable stress on the diurnal rhythms of sleep/wake behavior, the diurnal difference (dark-light) of \% REM, \% NREM, and \% wake were compared between groups following acute stressor exposure. Consistent with greater REM rebound in the light cycle observed in the home cage rats following acute stress (Figure 6A), both repeated fear $[F(1,30)=5.67 ; p=0.02]$ and acute stress $[F(2,30)=10.37$; $p=0.0004]$ reduced the diurnal difference of \% REM (Figure 7A). The flattening of the diurnal rhythm of \% REM sleep was present during the first, but was gone by the second (Figure 7B), $24 \mathrm{~h}$ period following acute stress. Acute stress reduced the diurnal difference of $\%$ NREM sleep $[F(2,30)=14.3 ; p<0.0001$; Figure 7C] and $\%$ wake $[F(2,30)=18.77 ; p<0.0001$; Figure $7 \mathbf{E}]$ during the first $24 \mathrm{~h}$ period following acute stress in both home cage and repeated fear-exposed rats. During the second $24 \mathrm{~h}$ period following acute stress, significant interactions between repeated fear and acute stress revealed that the flattening of the diurnal rhythm of both \% NREM sleep $[F(2,30)=4.88 ; p=0.01$; Figure 7D] and $\%$ wake $[F(2,30)=5.44 ; p=0.009$; Figure $7 F]$ persisted longer following acute stress in rats previously exposed to repeated fear. See Figure 7 for results of post hoc tests. 

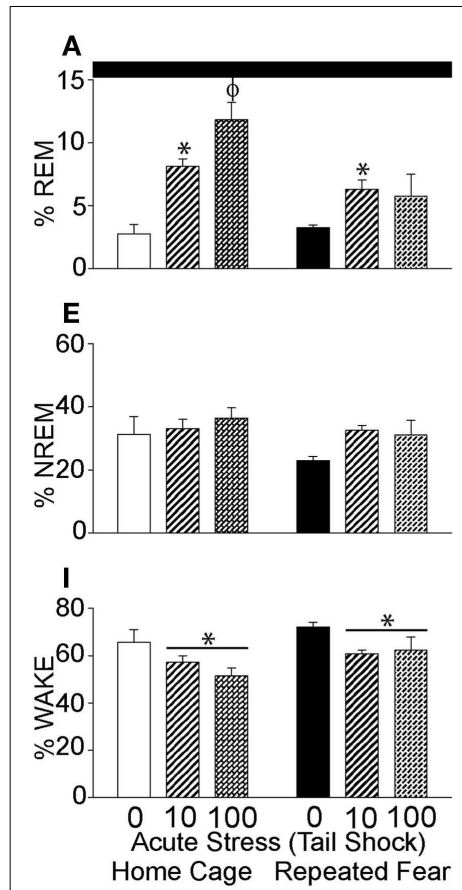

B

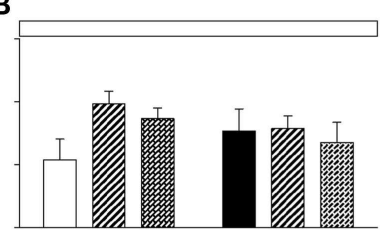

F

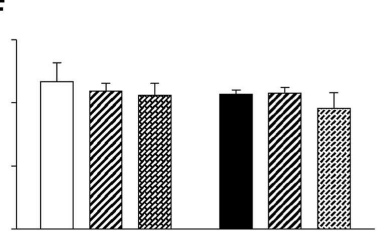

J

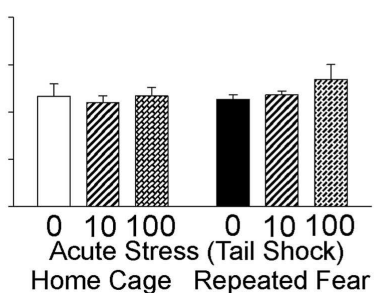

FIGURE 6 | Effects of repeated fear and acute stress on diurnal pattern of undisturbed home cage sleep/wake behavior. Following 22 days of no repeated fear (home cage) or repeated fear stress (repeated fear), rats were exposed to no acute stress (0), mild (10 uncontrollable tail shocks; 10 ), or severe (100 uncontrollable tails shocks; 100) acute stress. Percent time spent in rapid eye movement [REM; (A-D)] sleep, non-rapid eye movement [NREM;

C

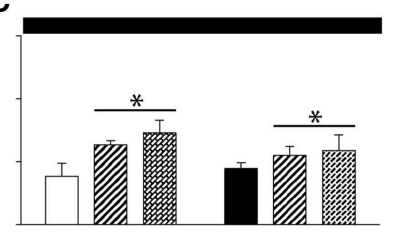

G

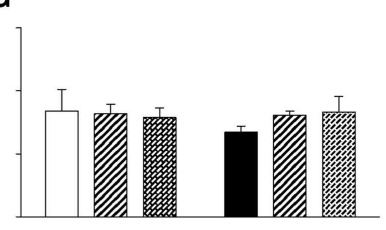

K

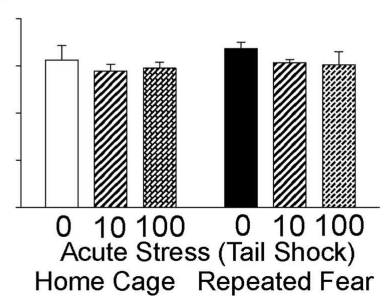

D

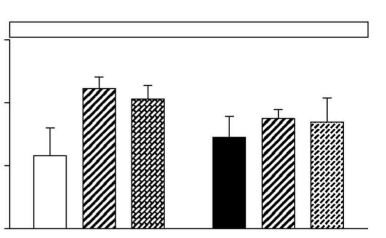

H

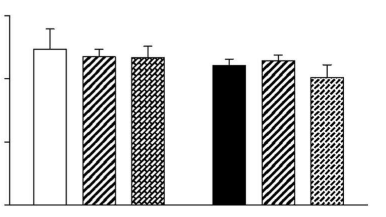

L

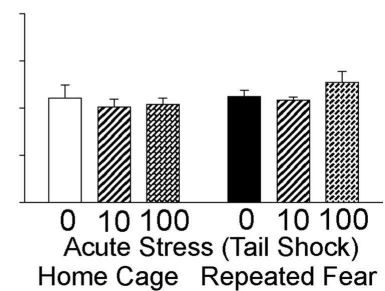

(E-H)] sleep, and wake (I-L) were determined in the home cage for 48 consecutive hours starting the dark cycle immediately following the day of acute stressor exposure. Averaged dark and light cycle data are reported in $12 \mathrm{~h}$ blocks. ${ }^{*} p<0.05$ relative to 0 groups (lines represent main effects of acute stress); $\phi p<0.05$ relative to all other groups. Dark bar represents $12 \mathrm{~h}$ dark cycle; white bar represents $12 \mathrm{~h}$ light cycle.

\section{DISCUSSION}

Here, we report that prior exposure to a repeated emotional stressor can increase anxiety-like behavior and induce prolonged sleep disruption following exposure to a subsequent acute, novel stressor. These observations add to our prior observations that repeated exposure to conditioned fear stress can sensitize $\mathrm{HR}$ and $\mathrm{CBT}$ responses to acute severe stress (18). Taken together, these data indicate that repeated exposure to conditioned fear stress can produce behaviors in rodents that resemble characteristics of stress-related psychiatric disorders, including sensitized autonomic responses (18), enhanced fear learning (Figures $\mathbf{3 B}$ and $\mathbf{4 B}$ ), and prolonged stressinduced flattening of biological rhythms including NREM sleep (Figure 7D) following exposure to a novel, acute uncontrollable stressor.

Exposure to severe (100 tail shocks), but not mild (10 tail shocks), acute uncontrollable stress reduced social exploratory behavior and increased freezing immediately following administration of foot shocks during fear conditioning in a novel environment (Figures 3 and 4). The observation that mild acute stress was insufficient to elicit anxiety-like behavior is consistent with prior work showing that greater than 50 uncontrollable tail shocks are required to activate serotonin (5-HT) neurons in the dorsal raphe nucleus (66); the putative mechanism by which acute severe stress transiently enhances fear conditioning $(67,68)$ and reduces social exploration $(45)$. Repeated fear

stress neither sensitized (Figure 3A) nor prolonged (Figure 4A) the effect of acute uncontrollable stress on social exploration. In contrast, a history of repeated fear stress enhanced shockelicited freezing, regardless of acute stressor exposure (Figures 3B and $4 B$ ). These data indicate that like a history of acute stress $(50,69,70)$, prior exposure to repeated fear stress can enhance the acquisition of a new fear memory. Similarly, clinical data indicate that patients with PTSD respond in an exaggerated manner to novel fear-eliciting stimuli and remember these aversive stimuli better than trauma-exposed controls without PTSD (10).

The fact that repeated fear stress increased anxiety-like behavior as measured by shock-elicited freezing but not social avoidance suggests that repeated fear stress impacts various anxiety-related behaviors differently. It is unlikely that a history of foot shock during repeated fear sensitized the anxiety response to subsequent foot shock during anxiety testing, because repeated exposure to homotypic stimuli typically lead to habituation, not sensitization, of the stress response to that stimuli $(20,71)$. Although the exaggerated fear and social avoidance produced by acute uncontrollable stress are thought to have similar mechanisms involving 5-HT and the amygdala $(55,72)$, repeated fear stress might impact a neural substrate capable of modulating fear- and not social-related anxiety behaviors. Although the hippocampus is an attractive candidate because of its involvement in contextual fear conditioning (73) and sensitivity to repeated stress (74), enhanced fear learning produced 

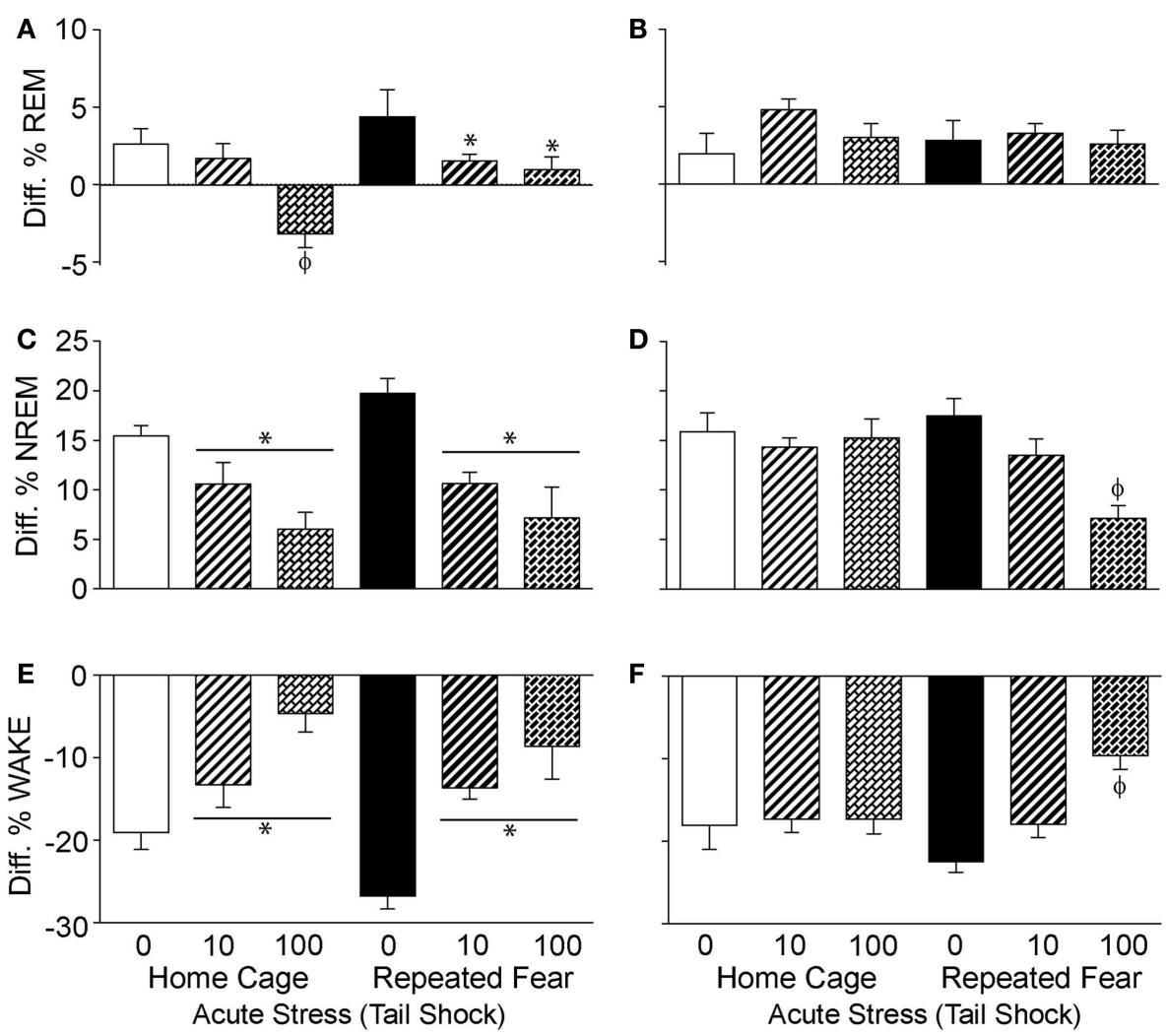

FIGURE 7 | Effects of repeated fear and acute stress on diurnal difference of sleep/wake behavior. Following 22 days of no repeated fear (home cage) or repeated fear stress (repeated fear), rats were exposed to no acute stress (0), mild (10 uncontrollable tail shocks; 10), or severe (100 uncontrollable tails shocks; 100) acute stress. Diurnal difference of \% rapid eye movement [REM; $(\mathbf{A}, \mathbf{B})$ ] sleep, non-rapid eye movement [NREM; (C,D)] sleep, and wake (E,F) were calculated by subtracting light cycle values from dark cycle values of sleep parameters measured in the home cage for $48 \mathrm{~h}$ starting the dark (active) cycle immediately following acute stressor exposure. The diurnal differences calculated from the first $24 \mathrm{~h}$ period starting the first active (dark) cycle immediately following acute stress are shown in the left panel $(\mathbf{A}, \mathbf{C}, \mathbf{E})$. The diurnal differences calculated from the second $24 \mathrm{~h}$ period following acute stress are shown in the right panel $\mathbf{( B , D , F ) . ~}{ }^{*} p<0.05$ relative to respective 0 groups (lines represent main effects of acute stress); $\phi p<0.05$ relative to all other groups. by repeated fear stress was observed immediately following shock administration during conditioning in a novel context, a time during which freezing is independent of the hippocampus (75). The prefrontal cortex is an important emotional control region that is known to undergo structural remodeling following repeated stress $(76,77)$ and can modulate fear expression $(78)$. Thus, the prefrontal cortex could be a structure through which repeated fear acts to enhance fear-related anxiety-like behavior. Consistent with this possibility are the observations of functional and structural deficits in the PFC of patients suffering from PTSD and depression (79-82).

Rats exposed to repeated conditioned fear had similar sleep patterns to rats exposed to home cage treatment in the absence of tail shock (the acute stress 0 groups), suggesting that repeated exposure to conditioned fear may not by itself impact sleep. This is surprising considering that both re-exposure to a cue (83) or a context (84) previously associated with a foot shock has been reported to reduce \% REM sleep during the inactive cycle. One reason for this discrepancy could be that the impact of fear conditioning on sleep habituates with time. Indeed, Kant et al. (85) reported that although total sleep time is initially reduced during repeated daily exposure to foot shock stress in the home cage, total sleep time returns to baseline levels by the 7 th day of stress. This explanation seems unlikely, however, considering that (1) the return to baseline sleep time following repeated foot shock reported in Ref. (85) was accompanied by a disruption of the normal diurnal rhythm of sleep and no such diurnal disruption following repeated fear stress was observed in the current study and (2) physiological and fear responses to the conditioned context were maintained throughout the duration of the study (18). Moreover, although extinction of fear reduces the impact of re-exposure to a contextual conditioned stimulus on REM sleep (84), fear extinction was prevented in the current study by administration of foot shocks when average freezing levels dropped below 50\%. An alternative explanation could be the strain of rat used in the study. Tang et al. (64) reported that relative to Lewis and Wistar rats, which exhibit a reduction in \% REM following re-exposure to a conditioned context, F344 rats display no such reduction. In fact, F344 rats displayed the 
greatest fear response and an increase in \% REM during the dark cycle following both acquisition and expression of contextual fear conditioning (86). The possibility remains, however, that repeated fear did disrupt sleep, but that disrupted sleep had resolved by the time analyses of sleep patterns began $24 \mathrm{~h}$ following the last exposure to the contextual CS. Indeed, Moreau et al. (87) report that changes in \% REM sleep produced by several weeks of mild stress disappeared progressively following termination of stress (87).

In contrast to the lack of observed effect of repeated fear stress on sleep, exposure to acute tail shock stress clearly impacted sleep. Similar to prior reports (88), acute stress reduced both \% REM and \% NREM sleep and increased \% wake during the hours immediately following acute stressor exposure. These data are consistent with our prior work reporting that this same stressor increases activity, HR, and CBT for several hours following stress $(18,47)$. Compared to home cage rats exposed to acute stress, rats previously exposed to repeated fear displayed a prolonged reduction in \% REM and \% NREM sleep for hours following stress. In fact, rats not exposed to repeated fear began to show signs of REM recovery by $5 \mathrm{~h}$ post-acute stress (Figure 5), a time point during which \% REM of rats exposed to repeated fear stress was still suppressed. Similar to the effect of acute stress observed in the current study, victims of acute traumatic injury display increased wake time following trauma (39). Interestingly, those trauma victims who also have disrupted REM sleep (increased frequency but very short duration REM sleep bouts) were also more likely to develop PTSD (39). Consistent with these clinical data, acute stress impacted REM sleep of rats previously exposed to repeated fear to a greater extent than home cage control rats, and this suppressed REM sleep was associated with the most robust shock-elicited freezing.

Rapid eye movement rebound [increased REM sleep after periods of REM suppression; (63)] has been reported to follow stressor exposure (64) and has been argued to represent an adaptive response to stress [for a review, see Ref. (65)]. Significant REM rebound was observed in home cage rats during several dark periods following acute stressor exposure (Figures 5A and 6C). In contrast, and despite the prolonged loss of REM sleep produced by acute stress in the rats exposed to repeated fear, rats exposed to repeated fear had impaired REM rebound (Figure 6A). Suppressed REM rebound following acute stress in rats exposed to repeated fear could thus represent a maladaptive response to acute novel stress that could contribute to vulnerability to stress-related disorders.

The mechanisms underlying REM rebound following stress have been reviewed (65) and could involve serotonin (88), corticosterone (89), prolactin $(65,90)$, or the central nucleus of the amygdala (91). Further work will be required to elucidate the mechanisms by which repeated fear exposure impairs REM rebound. It should be mentioned, however, that repeated fear stress does not result in exaggerated corticosterone responses to acute tail shock stress (18). Thus, differences in circulating corticosterone are unlikely to be involved in the observed suppression of the REM rebound.

In addition to prolonging sleep disruption immediately following acute stress and suppressing REM rebound, repeated fear stress produced a protracted disruption in the diurnal rhythm of NREM sleep elicited by acute stress. We have previously reported that prior repeated fear stress prolongs the acute stress-induced disruption of the diurnal rhythms of HR and CBT (18). Here, we extend those observations to include disruptions in diurnal rhythms of NREM. Although no differences in total \% NREM were observed following exposure to repeated or acute stress (Figure 6), prolonged damping of diurnal rhythms could itself be a precursor to mood disorders $(92,93)$. Indeed, disruption of sleep/wake cycles, such as occurs with seasonal affective disorders (94) and shift work $(95,96)$, can trigger mood-related problems in vulnerable individuals.

In conclusion, we present evidence that exposure to repeated fear stress increases selective measures of anxiety-like behavior, prolongs sleep disruption including REM and NREM suppression and NREM diurnal disruption, and impairs REM rebound following exposure to an acute, novel stressor. Sensitization of sleep disruption following acute stressors could contribute to the mechanisms by which a history of repeated stress leads to vulnerability to stress-related psychiatric disorders including anxiety.

\section{AUTHOR CONTRIBUTIONS}

Benjamin N. Greenwood and Robert S. Thompson conducted experiments, collected data, and co-authored the manuscript. Benjamin N. Greenwood, Robert S. Thompson, Mark R. Opp, and Monika Fleshner designed the experiments and analyzed data. Mark R. Opp and Monika Fleshner edited the final manuscript.

\section{ACKNOWLEDGMENTS}

This work was funded by DARPA W911NF-10-1-0050 (Monika Fleshner).

\section{REFERENCES}

1. Sapolsky RM. Why stress is bad for your brain. Science (1996) 273:749-50. doi:10.1126/science.273.5276.749

2. Vanitallie TB. Stress: a risk factor for serious illness. Metabolism (2002) 51:40-5. doi:10.1053/meta.2002.33191

3. Swaab DF, Bao AM, Lucassen PJ. The stress system in the human brain in depression and neurodegeneration. Ageing Res Rev (2005) 4:141-94. doi:10.1016/j.arr. 2005.03.003

4. Sapolsky RM. Glucocorticoids and hippocampal atrophy in neuropsychiatric disorders. Arch Gen Psychiatry (2000) 57:925-35. doi:10.1001/archpsyc.57.10. 925

5. Yehuda R. Biology of posttraumatic stress disorder. J Clin Psychiatry (2001) 62(Suppl 17):41-6.

6. van Praag HM. Can stress cause depression? World J Biol Psychiatry (2005) 6(Suppl 2):5-22. doi:10.1080/15622970510030018

7. Orr SP, Lasko NB, Shalev AY, Pitman RK. Physiologic responses to loud tones in Vietnam veterans with posttraumatic stress disorder. J Abnorm Psychol (1995) 104:75-82. doi:10.1037/0021-843X.104.1.75

8. Morgan CA III, Doran A, Steffian G, Hazlett G, Southwick SM. Stress-induced deficits in working memory and visuo-constructive abilities in special operations soldiers. Biol Psychiatry (2006) 60:722-9. doi:10.1016/j.biopsych.2006.04.021

9. Stam R. PTSD and stress sensitisation: a tale of brain and body Part 1: human studies. Neurosci Biobehav Rev (2007) 31:530-57. doi:10.1016/j.neubiorev.2006. 11.010

10. Orr SP, Metzger LJ, Lasko NB, Macklin ML, Peri T, Pitman RK. De novo conditioning in trauma-exposed individuals with and without posttraumatic stress disorder. J Abnorm Psychol (2000) 109:290-8. doi:10.1037/0021-843X.109.2.290

11. Orr SP, Metzger LJ, Lasko NB, Macklin ML, Hu FB, Shalev AY, et al. Physiologic responses to sudden, loud tones in monozygotic twins discordant for combat 
exposure: association with posttraumatic stress disorder. Arch Gen Psychiatry (2003) 60:283-8. doi:10.1001/archpsyc.60.3.283

12. Heim C, Newport DJ, Heit S, Graham YP, Wilcox M, Bonsall R, et al. Pituitaryadrenal and autonomic responses to stress in women after sexual and physical abuse in childhood. JAMA (2000) 284:592-7. doi:10.1001/jama.284.5.592

13. Morris MC, Compas BE, Garber J. Relations among posttraumatic stress disorder, comorbid major depression, and HPA function: a systematic review and meta-analysis. Clin Psychol Rev (2012) 32:301-15. doi:10.1016/j.cpr.2012.02.002

14. Bhatnagar S, Dallman M. Neuroanatomical basis for facilitation of hypothalamic-pituitary-adrenal responses to a novel stressor after chronic stress. Neuroscience (1998) 84:1025-39. doi:10.1016/S0306-4522(97)00577-0

15. Fernandes GA, Perks P, Cox NK, Lightman SL, Ingram CD, Shanks N. Habituation and cross-sensitization of stress-induced hypothalamic-pituitary-adrenal activity: effect of lesions in the paraventricular nucleus of the thalamus or bed nuclei of the stria terminalis. J Neuroendocrinol (2002) 14:593-602. doi:10.1046/j.1365-2826.2002.00819.x

16. Bhatnagar S, Vining C. Facilitation of hypothalamic-pituitary-adrenal responses to novel stress following repeated social stress using the resident/intruder paradigm. Horm Behav (2003) 43:158-65. doi:10.1016/S0018-506X(02)00011-9

17. Bhatnagar S, Mitchell JB, Betito K, Boksa P, Meaney MJ. Effects of chronic intermittent cold stress on pituitary adrenocortical and sympathetic adrenomedullary functioning. Physiol Behav (1995) 57:633-9. doi:10.1016/ 0031-9384(94)00161-8

18. Thompson RS, Strong PV, Clark PJ, Maslanik TM, Wright KP Jr, Greenwood $\mathrm{BN}$, et al. Repeated fear-induced diurnal rhythm disruptions predict PTSD-like sensitized physiological acute stress responses in F344 rats. Acta Physiol (2014) 211(2):447-65. doi:10.1111/apha.12239

19. Cuadra G, Zurita A, Lacerra C, Molina V. Chronic stress sensitizes frontal cortex dopamine release in response to a subsequent novel stressor: reversal by naloxone. Brain Res Bull (1999) 48:303-8. doi:10.1016/S0361-9230(98)00179-8

20. Weinberg MS, Bhatt AP, Girotti M, Masini CV, Day HE, Campeau S, et al. Repeated ferret odor exposure induces different temporal patterns of samestressor habituation and novel-stressor sensitization in both hypothalamicpituitary-adrenal axis activity and forebrain c-fos expression in the rat. Endocrinology (2009) 150:749-61. doi:10.1210/en.2008-0958

21. Murua VS, Gomez RA, Andrea ME, Molina VA. Shuttle-box deficits induced by chronic variable stress: reversal by imipramine administration. Pharmacol Biochem Behav (1991) 38:125-30. doi:10.1016/0091-3057(91)90599-W

22. Muscat R, Papp M, Willner P. Reversal of stress-induced anhedonia by the atypical antidepressants, fluoxetine and maprotiline. Psychopharmacology (1992) 109:433-8. doi:10.1007/BF02247719

23. Papadimitriou GN, Linkowski P. Sleep disturbance in anxiety disorders. Int Rev Psychiatry (2005) 17:229-36. doi:10.1080/09540260500104524

24. Taylor DJ, Lichstein KL, Durrence HH, Reidel BW, Bush AJ. Epidemiology of insomnia, depression, and anxiety. Sleep (2005) 28:1457-64.

25. Armitage R. Sleep and circadian rhythms in mood disorders. Acta Psychiatr Scand Suppl (2007) 433:104-15. doi:10.1111/j.1600-0447.2007.00968.x

26. Novati A, Roman V, Cetin T, Hagewoud R, Den Boer JA, Luiten PG, et al. Chronically restricted sleep leads to depression-like changes in neurotransmitter receptor sensitivity and neuroendocrine stress reactivity in rats. Sleep (2008) 31:1579-85.

27. Baron KG, Reid KJ. Circadian misalignment and health. Int Rev Psychiatry (2014) 26:139-54. doi:10.3109/09540261.2014.911149

28. Riemann D, Berger M, Voderholzer U. Sleep and depression - results from psychobiological studies: an overview. Biol Psychol (2001) 57:67-103. doi:10.1016/ S0301-0511(01)00090-4

29. Stein MB, Enns MW, Kryger MH. Sleep in nondepressed patients with panic disorder: II. Polysomnographic assessment of sleep architecture and sleep continuity. J Affect Disord (1993) 28:1-6. doi:10.1016/0165-0327(93)90071-Q

30. Arriaga F, Paiva T, Matos-Pires A, Cavaglia F, Lara E, Bastos L. The sleep of nondepressed patients with panic disorder: a comparison with normal controls. Acta Psychiatr Scand (1996) 93:191-4. doi:10.1111/j.1600-0447.1996.tb10630.x

31. Benca RM, Obermeyer WH, Thisted RA, Gillin JC. Sleep and psychiatric disorders. A meta-analysis. Arch Gen Psychiatry (1992) 49:651-68. doi:10.1001/ archpsyc.1992.01820080059010

32. Seifritz E. Contribution of sleep physiology to depressive pathophysiology. Neuropsychopharmacology (2001) 25:S85-8. doi:10.1016/S0893-133X(01)00319-0
33. Neylan TC, Otte C, Yehuda R, Marmar CR. Neuroendocrine regulation of sleep disturbances in PTSD. Ann N Y Acad Sci (2006) 1071:203-15. doi:10.1196/ annals.1364.015

34. Ross RJ, Ball WA, Dinges DF, Kribbs NB, Morrison AR, Silver SM, et al. Rapid eye movement sleep disturbance in posttraumatic stress disorder. Biol Psychiatry (1994) 35:195-202. doi:10.1016/0006-3223(94)91152-5

35. Mellman TA, Kumar A, Kulick-Bell R, Kumar M, Nolan B. Nocturnal/daytime urine noradrenergic measures and sleep in combat-related PTSD. Biol Psychiatry (1995) 38:174-9. doi:10.1016/0006-3223(94)00238-X

36. Mellman TA. Psychobiology of sleep disturbances in posttraumatic stress disorder. Ann N Y Acad Sci (1997) 821:142-9. doi:10.1111/j.1749-6632.1997. tb48275.x

37. Harvey AG, Jones C, Schmidt DA. Sleep and posttraumatic stress disorder: a review. Clin Psychol Rev (2003) 23:377-407. doi:10.1016/S0272-7358(03) 00032-1

38. Ross RJ, Ball WA, Sullivan KA, Caroff SN. Sleep disturbance as the hallmark of posttraumatic stress disorder. Am J Psychiatry (1989) 146:697-707.

39. Mellman TA, Bustamante V, Fins AI, Pigeon WR, Nolan B. REM sleep and the early development of posttraumatic stress disorder. Am J Psychiatry (2002) 159:1696-701. doi:10.1176/appi.ajp.159.10.1696

40. Pawlyk AC, Morrison AR, Ross RJ, Brennan FX. Stress-induced changes in sleep in rodents: models and mechanisms. Neurosci Biobehav Rev (2008) 32:99-117. doi:10.1016/j.neubiorev.2007.06.001

41. Sanford LD, Suchecki D, Meerlo P. Stress, arousal, and sleep. Curr Top Behav Neurosci (2014).doi:10.1007/7854_2014_314

42. Dallaspezia S, Benedetti F. Chronobiological therapy for mood disorders. Expert Rev Neurother (2011) 11:961-70. doi:10.1586/ern.11.61

43. Maturana MJ, Pudell C, Targa AD, Rodrigues LS, Noseda AC, Fortes MH, et al. REM sleep deprivation reverses neurochemical and other depressive-like alterations induced by olfactory bulbectomy. Mol Neurobiol (2014). doi:10.1007/ s12035-014-8721-x

44. Maier SF, Watkins LR. Stressor controllability and learned helplessness: the roles of the dorsal raphe nucleus, serotonin, and corticotropin-releasing factor. Neurosci Biobehav Rev (2005) 29:829-41. doi:10.1016/j.neubiorev.2005. 03.021

45. Christianson JP, Paul ED, Irani M, Thompson BM, Kubala KH, Yirmiya R, et al. The role of prior stressor controllability and the dorsal raphe nucleus in sucrose preference and social exploration. Behav Brain Res (2008) 193:87-93. doi:10.1016/j.bbr.2008.04.024

46. Maier SF. Role of fear in mediating shuttle escape learning deficit produced by inescapable shock. J Exp Psychol Anim Behav Process (1990) 16:137-49. doi:10.1037/0097-7403.16.2.137

47. Thompson RS, Christianson JP, Maslanik TM, Maier SF, Greenwood BN, Fleshner M. Effects of stressor controllability on diurnal physiological rhythms. Physiol Behav (2013) 15(112-113):32-9. doi:10.1016/j.physbeh.2013. 02.009

48. Sanford LD, Yang L, Wellman LL, Liu X, Tang X. Differential effects of controllable and uncontrollable footshock stress on sleep in mice. Sleep (2010) 33:621-30.

49. Moraska A, Fleshner M. Voluntary physical activity prevents stress-induced behavioral depression and anti-KLH antibody suppression. Am J Physiol Regul Integr Comp Physiol (2001) 281:R484-9.

50. Greenwood BN, Foley TE, Day HE, Campisi J, Hammack SH, Campeau S, et al. Freewheel running prevents learned helplessness/behavioral depression: role of dorsal raphe serotonergic neurons. J Neurosci (2003) 23:2889-98.

51. Greenwood BN, Spence KG, Crevling DM, Clark PJ, Craig WC, Fleshner M. Exercise-induced stress resistance is independent of exercise controllability and the medial prefrontal cortex. Eur J Neurosci (2013) 37:469-78. doi:10.1111/ejn.12044

52. Thompson RS, Strong PS, Fleshner M. Physiological consequences of repeated exposures to conditioned fear. Behav Sci (2012) 2:57-78. doi:10.3390/ bs2020057

53. Greenwood BN, Loughridge AB, Sadaoui N, Christianson JP, Fleshner M. The protective effects of voluntary exercise against the behavioral consequences of uncontrollable stress persist despite an increase in anxiety following forced cessation of exercise. Behav Brain Res (2012) 233:314-21. doi:10.1016/j.bbr.2012. 05.017 
54. Fanselow M, Lester L. A functional behavioristic approach to aversively motivated behavior: predatory imminence as a determinant of the topography of defensive behavior. In: Hillsdale NJ, Beecher RC, Bolles, MD, editors. Evolution and Learning. Hillsdale, NJ: Erlbaum (1988). p. 185-212.

55. Christianson JP, Ragole T, Amat J, Greenwood BN, Strong PV, Paul ED, et al. 5-hydroxytryptamine $2 \mathrm{C}$ receptors in the basolateral amygdala are involved in the expression of anxiety after uncontrollable traumatic stress. Biol Psychiatry (2010) 67:339-45. doi:10.1016/j.biopsych.2009.09.011

56. Maier SF, Watkins LR. Stressor controllability, anxiety, and serotonin. Cognit Ther Res (1998) 22:595-613. doi:10.1023/A:1018794104325

57. Greenwood BN, Strong PV, Brooks L, Fleshner M. Anxiety-like behaviors produced by acute fluoxetine administration in male Fischer 344 rats are prevented by prior exercise. Psychopharmacology (Berl) (2008) 199:209-22. doi:10.1007/s00213-008-1167-y

58. Baracchi F, Opp MR. Sleep-wake behavior and responses to sleep deprivation of mice lacking both interleukin-1 beta receptor 1 and tumor necrosis factoralpha receptor 1. Brain Behav Immun (2008) 22:982-93. doi:10.1016/j.bbi.2008. 02.001

59. Olivadoti MD, Opp MR. Effects of i.c.v. administration of interleukin-1 on sleep and body temperature of interleukin-6-deficient mice. Neuroscience (2008) 153:338-48. doi:10.1016/j.neuroscience.2008.02.008

60. Paxinos G, Watson C. The Rat Brain in Stereotaxic Coordinates. Elsevier (2006).

61. Greenwood BN, Strong PV, Loughridge AB, Day HE, Clark PJ, Mika A, et al. 5 -HT(2C) receptors in the basolateral amygdala and dorsal striatum are a novel target for the anxiolytic and antidepressant effects of exercise. PLoS One (2012) 7:e46118. doi:10.1371/journal.pone.0046118

62. Morrow JD, Opp MR. Diurnal variation of lipopolysaccharide-induced alterations in sleep and body temperature of interleukin-6-deficient mice. Brain Behav Immun (2005) 19:40-51. doi:10.1016/j.bbi.2004.04.001

63. Dement W. The effect of dream deprivation. Science (1960) 131:1705-7. doi:10.1126/science.131.3415.1705

64. Tang X, Liu X, Yang L, Sanford LD. Rat strain differences in sleep after acute mild stressors and short-term sleep loss. Behav Brain Res (2005) 160:60-71. doi:10.1016/j.bbr.2004.11.015

65. Suchecki D, Tiba PA, Machado RB. REM sleep rebound as an adaptive response to stressful situations. Front Neurol (2012) 3:41. doi:10.3389/fneur.2012.00041

66. Takase LF, Nogueira MI, Bland ST, Baratta M, Watkins LR, Maier SF, et al. Effect of number of tailshocks on learned helplessness and activation of serotonergic and noradrenergic neurons in the rat. Behav Brain Res (2005) 162(2):299-306. doi:10.1016/j.bbr.2005.04.008

67. Maier SF, Grahn RE, Kalman BA, Sutton LC, Wiertelak EP, Watkins LR The role of the amygdala and dorsal raphe nucleus in mediating the behavioral consequences of inescapable shock. Behav Neurosci (1993) 107:377-88. doi:10.1037/0735-7044.107.2.377

68. Maier SF, Grahn RE, Watkins LR. 8-OH-DPAT microinjected in the region of the dorsal raphe nucleus blocks and reverses the enhancement of fear conditioning and interference with escape produced by exposure to inescapable shock. Behav Neurosci (1995) 109:404-12. doi:10.1037/0735-7044.109.3.404

69. Rau V, Decola JP, Fanselow MS. Stress-induced enhancement of fear learning: an animal model of posttraumatic stress disorder. Neurosci Biobehav Rev (2005) 29:1207-23. doi:10.1016/j.neubiorev.2005.04.010

70. Baratta MV, Christianson JP, Gomez DM, Zarza CM, Amat J, Masini CV, et al. Controllable versus uncontrollable stressors bi-directionally modulate conditioned but not innate fear. Neuroscience (2007) 146:1495-503. doi:10.1016/j. neuroscience.2007.03.042

71. Grissom N, Bhatnagar S. Habituation to repeated stress: get used to it. Neurobiol Learn Mem (2009) 92:215-24. doi:10.1016/j.nlm.2008.07.001

72. Christianson JP, Greenwood BN. Stress-protective neural circuits: not all roads lead through the prefrontal cortex. Stress (2014) 17:1-12. doi:10.3109/10253890. 2013.794450

73. Rudy JW, Barrientos RM, O'Reilly RC. Hippocampal formation supports conditioning to memory of a context. Behav Neurosci (2002) 116:530-8. doi:10.1037/0735-7044.116.4.530

74. McEwen BS. Plasticity of the hippocampus: adaptation to chronic stress and allostatic load. Ann N Y Acad Sci (2001) 933:265-77. doi:10.1111/j.1749-6632. 2001.tb05830.x
75. Kim JJ, Rison RA, Fanselow MS. Effects of amygdala, hippocampus, and periaqueductal gray lesions on short- and long-term contextual fear. Behav Neurosci (1993) 107:1093-8. doi:10.1037/0735-7044.107.6.1093

76. Cook SC, Wellman CL. Chronic stress alters dendritic morphology in rat medial prefrontal cortex. J Neurobiol (2004) 60:236-48. doi:10.1002/neu. 20025

77. Goldwater DS, Pavlides C, Hunter RG, Bloss EB, Hof PR, Mcewen BS, et al. Structural and functional alterations to rat medial prefrontal cortex following chronic restraint stress and recovery. Neuroscience (2009) 164:798-808. doi:10.1016/j.neuroscience.2009.08.053

78. Sierra-Mercado D, Padilla-Coreano N, Quirk GJ. Dissociable roles of prelimbic and infralimbic cortices, ventral hippocampus, and basolateral amygdala in the expression and extinction of conditioned fear. Neuropsychopharmacology (2011) 36:529-38. doi:10.1038/npp.2010.184

79. Drevets WC, Price JL, Furey ML. Brain structural and functional abnormalities in mood disorders: implications for neurocircuitry models of depression. Brain Struct Funct (2008) 213:93-118. doi:10.1007/s00429-008-0189-x

80. Koenigs M, Grafman J. Posttraumatic stress disorder: the role of medial prefrontal cortex and amygdala. Neuroscientist (2009) 15:540-8. doi:10.1177/ 1073858409333072

81. Li L, Wu M, Liao Y, Ouyang L, Du M, Lei D, et al. Grey matter reduction associated with posttraumatic stress disorder and traumatic stress. Neurosci Biobehav $\operatorname{Rev}(2014)$ 43C:163-72. doi:10.1016/j.neubiorev.2014.04.003

82. Meng Y, Qiu C, Zhu H, Lama S, Lui S, Gong Q, et al. Anatomical deficits in adult posttraumatic stress disorder: a meta-analysis of voxel-based morphometry studies. Behav Brain Res (2014) 270C:307-15. doi:10.1016/j.bbr. 2014.05.021

83. Jha SK, Brennan FX, Pawlyk AC, Ross RJ, Morrison AR. REM sleep: a sensitive index of fear conditioning in rats. Eur J Neurosci (2005) 21:1077-80. doi:10.1111/j.1460-9568.2005.03920.x

84. Wellman LL, Yang L, Tang X, Sanford LD. Contextual fear extinction ameliorates sleep disturbances found following fear conditioning in rats. Sleep (2008) 31:1035-42.

85. Kant GJ, Pastel RH, Bauman RA, Meininger GR, Maughan KR, Robinson TN III, et al. Effects of chronic stress on sleep in rats. Physiol Behav (1995) 57:359-65. doi:10.1016/0031-9384(94)00241-V

86. Tang X, Yang L, Sanford LD. Rat strain differences in freezing and sleep alterations associated with contextual fear. Sleep (2005) 28:1235-44.

87. Moreau JL, Scherschlicht R, Jenck F, Martin JR. Chronic mild stress-induced anhedonia model of depression; sleep abnormalities and curative effects of electroshock treatment. Behav Pharmacol (1995) 6:682-7. doi:10.1097/00008877199511000-00003

88. Rachalski A, Alexandre C, Bernard JF, Saurini F, Lesch KP, Hamon M, et al. Altered sleep homeostasis after restraint stress in 5-HTT knock-out male mice: a role for hypocretins. J Neurosci (2009) 29:15575-85. doi:10.1523/JNEUROSCI. 3138-09.2009

89. Bonnet C, Marinesco S, Debilly G, Kovalzon V, Cespuglio R. Influence of a 1-h immobilization stress on sleep and CLIP (ACTH(18-39)) brain contents in adrenalectomized rats. Brain Res (2000) 853:323-9. doi:10.1016/S00068993(99)02313-6

90. Machado RB, Tufik S, Suchecki D. Chronic stress during paradoxical sleep deprivation increases paradoxical sleep rebound: association with prolactin plasma levels and brain serotonin content. Psychoneuroendocrinology (2008) 33:1211-24. doi:10.1016/j.psyneuen.2008.06.007

91. Sanford LD, Parris B, Tang X. GABAergic regulation of the central nucleus of the amygdala: implications for sleep control. Brain Res (2002) 956:276-84. doi:10.1016/S0006-8993(02)03552-7

92. Emens J, Lewy A, Kinzie JM, Arntz D, Rough J. Circadian misalignment in major depressive disorder. Psychiatry Res (2009) 168:259-61. doi:10.1016/j.psychres. 2009.04.009

93. Hasler BP, Buysse DJ, Kupfer DJ, Germain A. Phase relationships between core body temperature, melatonin, and sleep are associated with depression severity: further evidence for circadian misalignment in non-seasonal depression. Psychiatry Res (2010) 178:205-7. doi:10.1016/j.psychres.2010.04. 027

94. Howland RH. An overview of seasonal affective disorder and its treatment options. Phys Sportsmed (2009) 37:104-15. doi:10.3810/psm.2009.12.1748 
95. Cole RJ, Loving RT, Kripke DF. Psychiatric aspects of shiftwork. Occup Med (1990) 5:301-14.

96. Scott AJ, Monk TH, Brink LL. Shiftwork as a risk factor for depression: a pilot study. Int J Occup Environ Health (1997) 3:S2-9.

Conflict of Interest Statement: The authors declare that the research was conducted in the absence of any commercial or financial relationships that could be construed as a potential conflict of interest.

Received: 01 August 2014; accepted: 30 September 2014; published online: 20 October 2014.
Citation: Greenwood BN, Thompson RS, Opp MR and Fleshner M (2014) Repeated exposure to conditioned fear stress increases anxiety and delays sleep recovery following exposure to an acute traumatic stressor. Front. Psychiatry 5:146. doi: 10.3389/fpsyt.2014.00146

This article was submitted to Affective Disorders and Psychosomatic Research, a section of the journal Frontiers in Psychiatry.

Copyright $\odot 2014$ Greenwood, Thompson, Opp and Fleshner. This is an open-access article distributed under the terms of the Creative Commons Attribution License (CC $B Y)$. The use, distribution or reproduction in other forums is permitted, provided the original author(s) or licensor are credited and that the original publication in this journal is cited, in accordance with accepted academic practice. No use, distribution or reproduction is permitted which does not comply with these terms. 